Article

\title{
Fourier Transform Mass Spectrometry and Nuclear Magnetic Resonance Analysis for the Rapid and Accurate Characterization of Hexacosanoylceramide
}

\author{
Charles W. Ross III ${ }^{1, *}$, William J. Simonsick Jr. ${ }^{2, \dagger}$, Michael J. Bogusky ${ }^{1}$, Recep W. Celikay ${ }^{2, \ddagger}$, \\ James P. Guare ${ }^{1}$ and Randall C. Newton ${ }^{1}$ \\ 1 Merck \& Co. Inc., Merck Research Laboratories, Dept. of Medicinal Chemistry, West Point, PA 19486, USA; \\ mjbogusky@gmail.com (M.J.B.); jpguare@gmail.com (J.P.G.) \\ 2 DuPont Marshall R \& D Laboratories, Philadelphia, PA 19146, USA; \\ William.Simonsick@lubrizol.com (W.J.S.); recep.w.celikay@dupont.com (R.W.C.) \\ * Correspondence: cwrossiii@gmail.com \\ † Current Address: Lubrizol Advanced Materials, Inc., 9911 Brecksville Rd., Brecksville, OH 44141-3201, USA \\ $\ddagger$ Current Address: DuPont Corporate Center for Analytical Sciences, DuPont Experimental Station, \\ 200 Powder Mill Rd., PO Box 8352, Wilmington, DE 19803, USA
}

Academic Editor: Laszlo Prokai

Received: 29 February 2016; Accepted: 16 May 2016; Published: 28 June 2016

\begin{abstract}
Ceramides are a central unit of all sphingolipids which have been identified as sites of biological recognition on cellular membranes mediating cell growth and differentiation. Several glycosphingolipids have been isolated, displaying immunomodulatory and anti-tumor activities. These molecules have generated considerable interest as potential vaccine adjuvants in humans. Accurate analyses of these and related sphingosine analogues are important for the characterization of structure, biological function, and metabolism. We report the complementary use of direct laser desorption ionization (DLDI), sheath flow electrospray ionization (ESI) Fourier transform ion cyclotron resonance mass spectrometry (FTICR MS) and high-field nuclear magnetic resonance (NMR) analysis for the rapid, accurate identification of hexacosanoylceramide and starting materials. DLDI does not require stringent sample preparation and yields representative ions. Sheath-flow ESI yields ions of the product and byproducts and was significantly better than monospray ESI due to improved compound solubility. Negative ion sheath flow ESI provided data of starting materials and products all in one acquisition as hexacosanoic acid does not ionize efficiently when ceramides are present. NMR provided characterization of these lipid molecules complementing the results obtained from MS analyses. NMR data was able to differentiate straight chain versus branched chain alkyl groups not easily obtained from mass spectrometry.
\end{abstract}

Keywords: ceramides; sphingolipids; adjuvants; Fourier transform ion cyclotron resonance mass spectrometry (FTICR MS); nuclear magnetic resonance (NMR); direct laser desorption ionization; electrospray ionization

\section{Introduction}

Ceramide is a central unit of all sphingolipids, a large class of membrane lipids that function as recognition sites on cell membrane surfaces and constitute a major component of nerve tissue. Ceramides formed by the metabolism of sphingolipids may function as signal transducers to mediate a variety of cellular processes. Previous studies suggest that ceramide is a key signaling molecule generated in response to stresses that mediate growth arrest, differentiation, apoptosis or an immune response [1-4]. Several glycosphingolipids have been identified that display immunomodulatory [5-7] and anti-tumor activities $[8,9]$. Considerable interest has been generated in the use of these molecules 
as potential adjuvants designed to enhance the immune response in humans when administered with vaccine preparations. Much effort is being devoted to the development of both safe and clinically-effective adjuvants for use in humans. A variety of analytical and enzymological techniques have been used to identify, characterize, and quantify these compounds [10].

Lipid and ceramide analyses have been performed by various techniques such as: derivatization with an ultraviolet chromophore or fluorescence tag for subsequent high performance liquid chromatography (HPLC) separation and UV analysis [11-16], HPLC separation with evaporative light scattering detection [17-20], fast atom bombardment ionization [21,22], and electrospray ionization mass spectrometry [23-30]. Derivatization of the hydroxyl or amine groups with a chromophore suitable for UV detection provides reliable quantitative results but is time consuming. The derivatized samples are typically unstable and must be analyzed rapidly before decomposition. Evaporative light scattering detection with HPLC separation provides direct analysis without derivatization and is ideal for compounds that lack a chromophore. Detection is a function of the amount of light scattered from the molecule and relates to the size or mass of the molecule. Quantitation is only possible using standards since a direct relationship to mass is not possible. Thin layer chromatography (TLC) is more commonly used for the separation and identification of ceramides [31]. Spot identification is usually done by staining and quantitation by densitometry. The capacity of TLC is low compared to HPLC for sufficient separation. Identification in all of these cases is determined by time or place of elution. Mass spectrometric detection has shown the most promise in identifying ceramides by mass measurement and product ion analysis from collisionally activated dissociation $[21,22,29,30]$. Normal phase HPLC coupled to atmospheric pressure chemical ionization (APCI) proved useful in the measurement of ceramides owing to the lack of salt adduction and ion suppression with APCI. However, APCI can induce fragmentation and one must be cautious of applying high voltages to the LC eluent flow of isooctane and ethyl acetate used to solubilize these samples [32]. Recently, an optimized coaxial electrospray ionization method [33], originally applied to polymer analysis [34], demonstrated superior results over conventional mass spectrometry methods for phytosphingosine, hexacosanoic acid and their reaction products. In all cases, we found that sample preparation is critical to obtaining reasonable results.

Herein, we discuss the rapid analysis of phytosphingosine and its products from reaction with hexacosanoic acid. Direct laser desorption ionization and sheath flow electrospray ionization do not require stringent sample preparation. These methods are compared to standard single needle electrospray ionization. High field NMR analyses are used for structural confirmation and to determine approximate relative ratios of starting material to desired product. High resolution ${ }^{13} \mathrm{C}$ NMR analysis is used to identify straight chain or branched chain alkyl groups, which is not easily determined by MS or MS/MS experiments. Using these sophisticated analytical techniques, all the starting materials and reaction products can be identified and quantified.

\section{Results and Discussion}

\subsection{Analysis of Starting Materials}

Prior to monitoring the reaction of hexacosanoic acid and phytosphingosine, both starting materials were analyzed. Standard electrospray ionization of phytosphingosine, in which the analyte is dissolved in acetonitrile:water:acetic acid (50:50:0.1\% $v / v)$ and is sprayed through a central needle that is sheathed only in nitrogen gas for pneumatic assistance yielded a strong signal for $[\mathrm{M}+\mathrm{H}]^{+}$ at $m / z 318.2994$ (theoretical 318.2989) with a signal to noise ratio (S/N) of 7000. Slightly raising the nozzle voltage provided in-source fragmentation with consecutive losses of water $m / z 300.2846$ and 282.2787, Figure 1 . The structure and purity of phytosphingosine were also confirmed by NMR. Proton and carbon chemical shift assignments were made from the analysis of COSY, HMQC and HMBC spectra (using $\sim 1.0 \mathrm{mg}$ phytosphingosine dissolved in $0.65 \mathrm{~mL} \mathrm{DMSO}-d_{6}$. as sample). The aliphatic region (0.8-1.8 ppm) of the proton spectrum integrates for 29 protons, 13 methylene groups, and a 
single methyl resonance are observed which are consistent with a straight chain $\left(\mathrm{CH}_{2}\right)_{13} \mathrm{CH}_{3}$ alkyl side chain. The one-dimensional proton-decoupled carbon spectrum also confirms the presence of a straight chain alkyl side chain. The $0.7 \mathrm{ppm}$ chemical shift dispersion observed for the central nine carbons of the alkyl chain indicate that no branching is present. The amino $\mathrm{NH}_{2}$ protons are visible as a very broad resonance at $\sim 5.65 \mathrm{ppm}$. The ${ }^{1} \mathrm{H}$ and ${ }^{13} \mathrm{C}$ chemical shifts, proton coupling constants, ${ }^{1} \mathrm{H}-{ }^{1} \mathrm{H}$ COSY correlations and heteronuclear ${ }^{1} \mathrm{H}^{13}{ }^{13} \mathrm{C}$ - and 3-bond correlations confirm the structure depicted in Scheme 1. NMR and mass spectral data were in agreement, indicating that the phytosphingosine starting material was pure with trace impurities limited to $<<5 \%$.

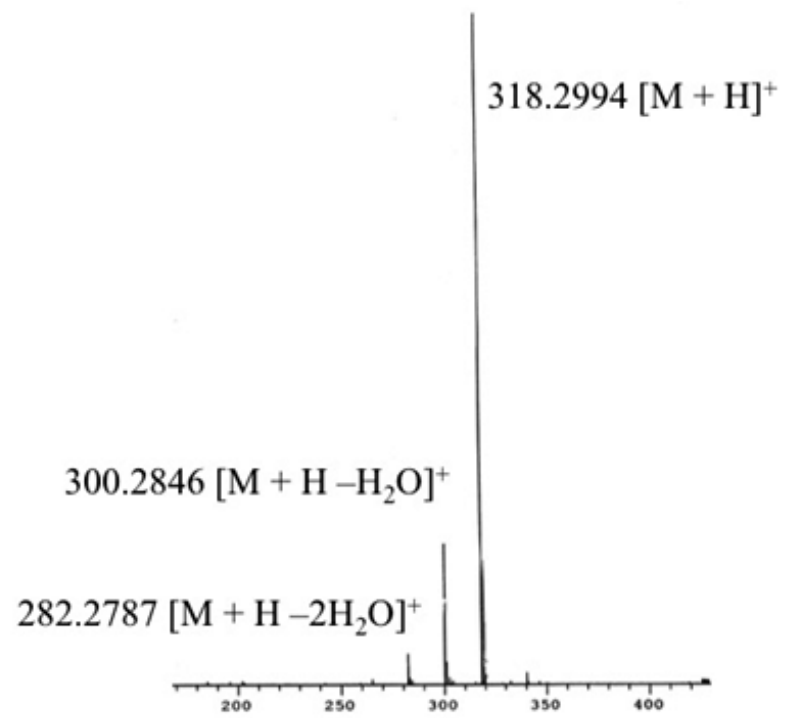

Figure 1. Standard monoelectrospray ionization mass spectrum of phytosphingosine. Increased nozzle/skimmer potentials yield neutral water loss.
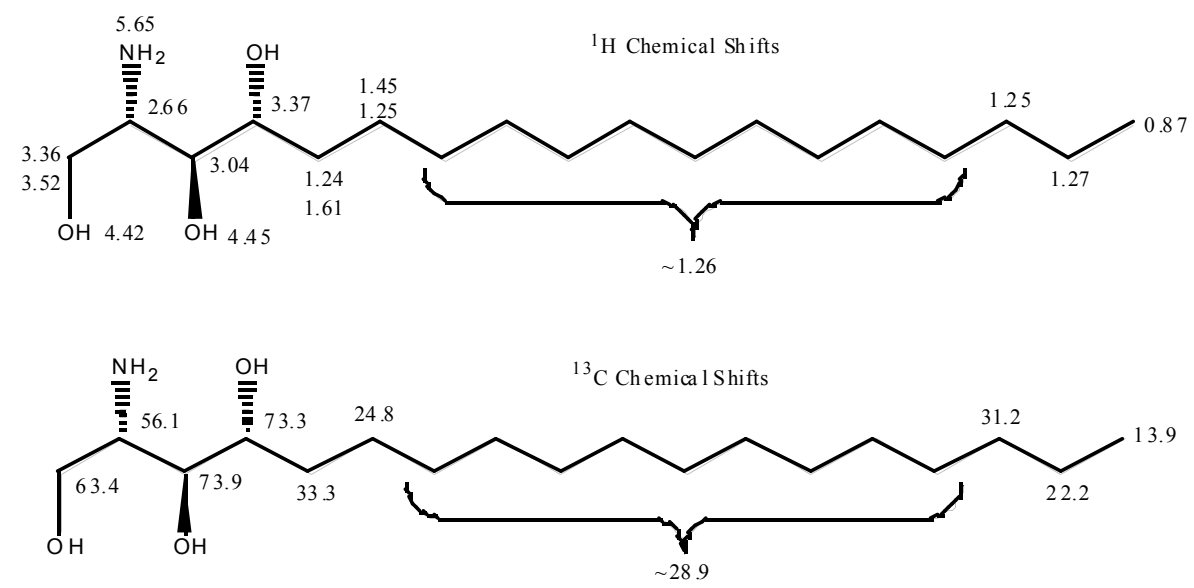

Scheme 1. Phytosphingosine NMR chemical shifts.

Due to the long aliphatic chain of the hexacosanoic acid, this starting material was not soluble in acetonitrile:water. The sample dissolved in tetrahydrofuran (THF) yielded $[\mathrm{M}-\mathrm{H}+2 \mathrm{Na}]^{+}$at $m / z 441.3699$ (theoretical 441.3679) and the cluster species [2M $-2 \mathrm{H}+3 \mathrm{Na}]^{+}, m / z 859.7601$ (data not shown for brevity).

\subsection{Analysis of Reaction Products}

Attempts were made to monitor the $N$-[3-(dimethylamino)propyl]- $N^{\prime}$-ethylcarbodiimide hydrochloride/1H-1,2,3-benzotriazol-1-ol hydrate (EDC/HOBT) reaction and acid chloride reaction 
products by standard monospray ESI. Strong signals were observed for phytosphingosine; however, no signal was observed for the hexacosanoylceramide product expected at $m / z 696,[\mathrm{M}+\mathrm{H}]^{+}$. These samples were only partially soluble in an acetonitrile:water mixture. In order to solubilize the hexacosanoic acid starting material and ceramide, approximately $1 \mathrm{~mL}$ of tetrahydrofuran (THF) was added to the $1 \mathrm{~mL}$ sample solution until dissolution was complete. The solubilized sample was sprayed by standard single needle design. Despite optimization of gas flow rates and nozzle/skimmer voltages, which were skewed towards higher nozzle voltages, only a minor signal was observed at $\mathrm{m} / z$ 696.6891 (theoretical 696.6864) with an $S / N$ of 10 and a ${ }^{13} \mathrm{C}$ isotope $S / N$ of 4.0. This signal intensity is insufficient to unambiguously identify the product. Since no analytical methods were available to us to verify the product at the onset of the investigations, we sought alternate methods of ionization that we have at our disposal. The ionization schemes, attributes and pitfalls found for ceramides are discussed below.

\subsection{Direct Laser Desorption Ionization Fourier Transform Ion Cyclotron Resonance Mass Spectrometry (FTICR MS) Analysis}

Prior experience with highly apolar, water insoluble compounds, such as acrylic polymers, demonstrated that direct laser desorption ionization (DLDI) provides a rapid means of ionizing and characterizing such samples $[35,36]$. The technique is simply described as "dilute and shoot", yielding representative data of polymer multicomponent samples. Matrix-assisted laser desorption ionization (MALDI) FTICR MS analysis of phospholipids has been successfully performed to yield high quality results. The identification of a proper matrix for the compounds is essential to the analysis [37]. DLDI does not suffer from matrix compatibility problems because the solubilized sample is placed directly on a cellulose substrate without a chemical matrix. Figure 2 shows that DLDI of the EDC/HOBT reaction yielded a significant signal at $m / z 734.7$ (theoretical 734.6), the targeted ceramide product, $[\mathrm{M}+\mathrm{K}]^{+}$, with an $S / N$ of $\sim 200$. The cellulose substrate which has strong absorbance at $10.6 \mu \mathrm{m}\left(\mathrm{CO}_{2}\right.$ emission wavelength) functions as our matrix. The reaction mixture of hexacosanoyl chloride with phytosphingosine displayed additional signals at $m / z 1113$ and 1491 , corresponding to the 2nd and 3rd covalent additions of hexacosanoyl to phytosphingosine (Figure 3). Accordingly, the EDC/HOBT coupling reaction was determined to be the best and was monitored further. Direct laser desorption mass spectrometry provided a rapid method to identify products from both reactions in a simple manner that takes less than twenty minutes to perform including sample preparation.

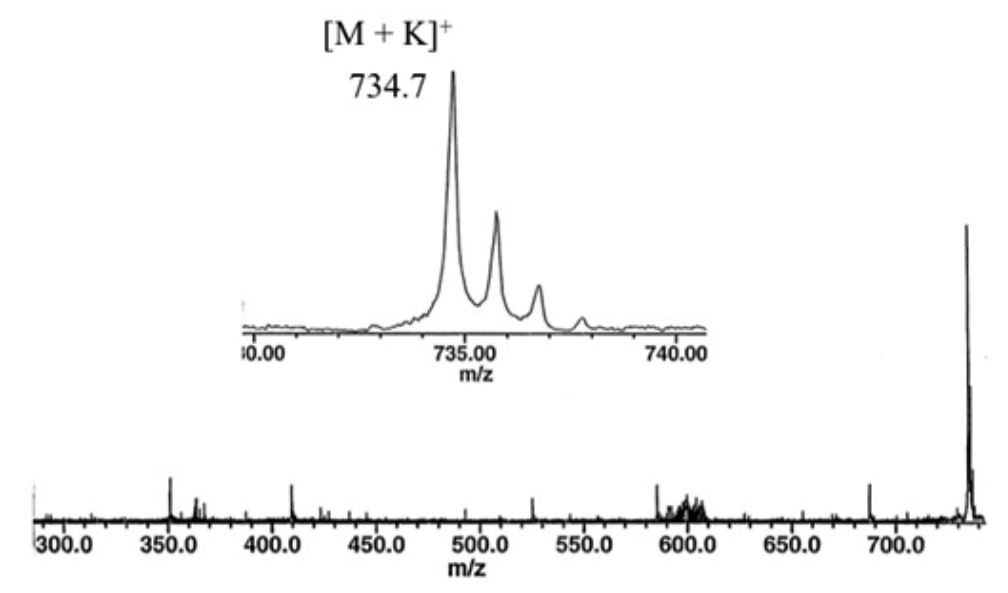

Figure 2. Direct laser desorption ionization of hexacosanoylceramide reaction mixture from EDC/HOBT coupling, reaction A. $[\mathrm{M}+\mathrm{K}]^{+}$is observed for the product, stable isotopic distribution is in agreement for the product.

From the data, it is apparent that the solid cellulose substrate that holds the sample can randomly yield significant matrix ions, which could interfere with analysis. Second, the resolving power is much 
lower than expected for a 3T FTICR MS instrument due to laser desorption's ionization mechanism and ion capture which yields ions that are not centered in the ICR cell, the homogeneous region of the magnetic field. Without quadrupolar axialization and collisional cooling to center the ions [38,39], the resolving power of DLDI is limited to $\sim 3500$ as the transient damps quickly to noise within $0.3 \mathrm{~s}$. Mass measurement accuracy without internal reference ions were approximately $0.1 \mathrm{Da}$, dependent on mass measured. It is possible to use the matrix ions as an internal reference and achieve mass accuracies of $\pm 0.01 \mathrm{Da}$; in this case, the observed mass was $m / z 734.630$ (theor. 734.642 ), data not shown for brevity. DLDI is also not amenable to online chromatography, which may be required due to sample solubility differences and the concentration ranges of the compounds under study. However, sample fractions could be collected and easily analyzed off-line.

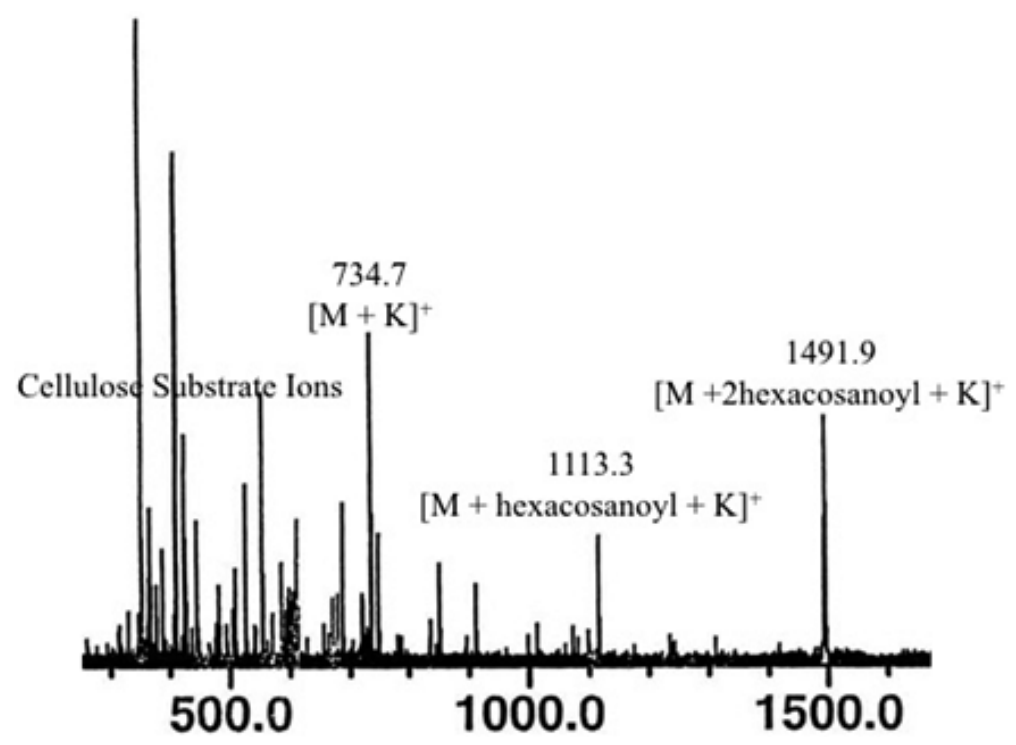

Figure 3. Direct laser desorption ionization (DLDI) mass spectrum of the hexacosanoylchloride coupling reaction $\mathrm{B} .[\mathrm{M}+\mathrm{K}]^{+}$, desired one covalent addition is observed for the product along with second and third covalent additions of hexacosanoyl to phytosphingosine.

\subsection{Sheath Flow Electrospray Ionization}

Sheath flow electrospray ionization was developed in the mid-1990s to improve ionization of intractable compounds by single needle ESI and to provide a simplified means to interface chromatographic methods such as gel permeation chromatography [34,40,41]. Prior attempts to improve electrospray ionization efficiency by adding sodium or potassium to the sample before separation showed that it can degrade the chromatography and compromise the column [42]. In sheath flow ESI, a triple needle design allows one to infuse the sample in an appropriate solvent or the chromatographic eluent through the center needle. The first sheath contains the ionization modifier solution such as sodium iodide or potassium iodide in methanol, all contained within the outer sheath of the nitrogen carrier gas. Separation of the ionizing agent and the analyte provides enhanced solubility of both components without the need to identify a solvent mixture that can solubilize both components in one vial. Ionization takes place in the Taylor cone through evaporation of solvents and mild ion/molecule association. Using this triple needle strategy, Ramjit et al. demonstrated improved analysis of apolar compounds [33].

Figure 4 shows the sheath flow ES FTICR mass spectrum of the EDC crude reaction mixture. Strong signals are observed for $[\mathrm{M}+\mathrm{Na}]^{+}$and $[2 \mathrm{M}+\mathrm{Na}]^{+}$. Improved resolving power $(\sim 10,000)$ and mass accuracy $(2 \mathrm{mDa})$ is achieved by this technique with FTICR because the collected electrosprayed ions are now centered in the ICR cell. 


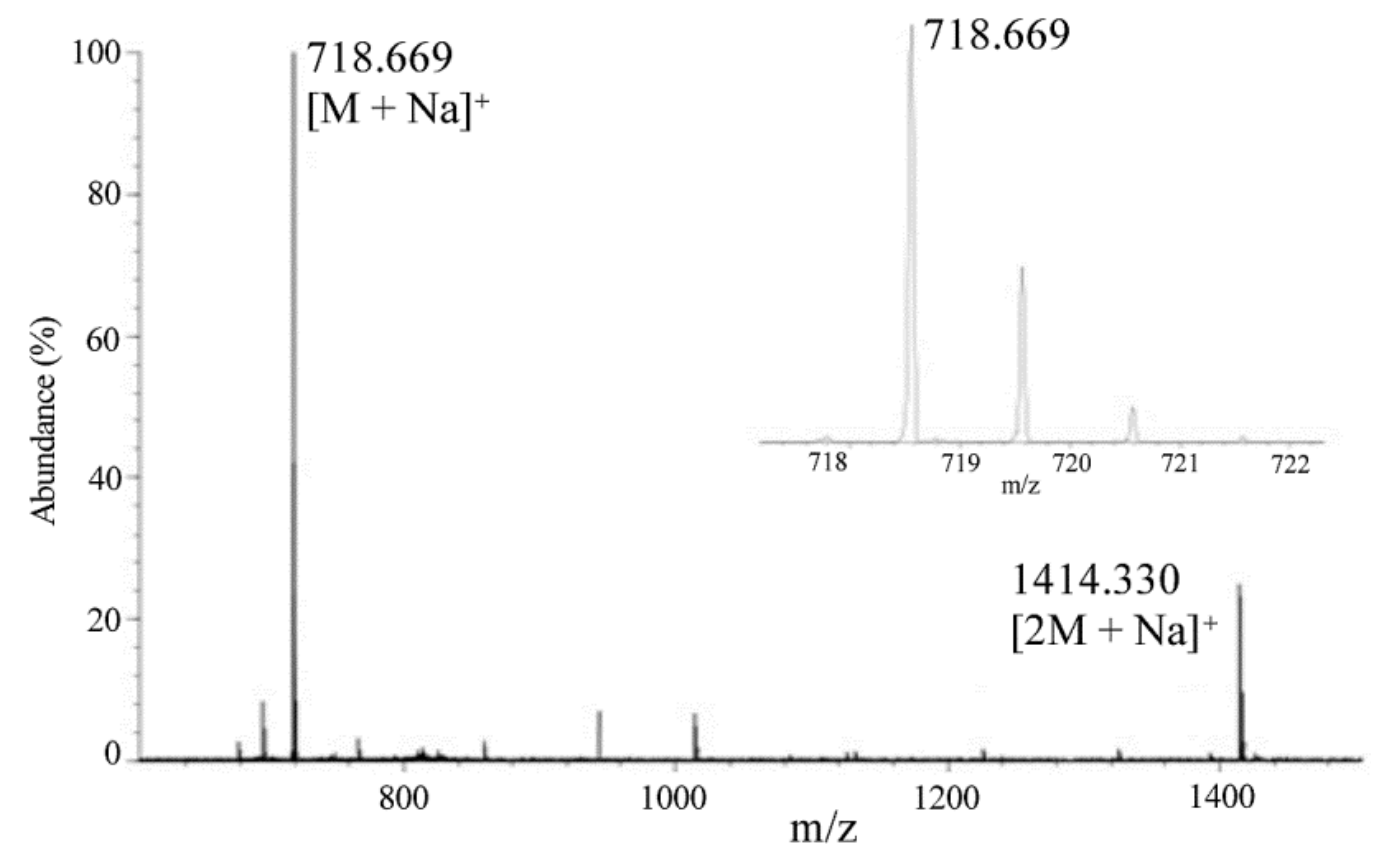

Figure 4. Sheath flow ESI mass spectrum of reaction A, mixture. $[\mathrm{M}+\mathrm{Na}]^{+}$is observed for the product. Note the improved resolving power compared to data in Figure 2.

\subsection{Final Analyses}

With improved mass spectral methods and a more thorough understanding of the sample complexity, the reaction chemistry was re-evaluated. In all cases, the combination of DLDI, Sheath Flow ESI-FTICR MS, and high field NMR analyses provided data consistent with the starting materials and desired product. NMR data acquired on THF solubilized samples generated complementary results. The ${ }^{1} \mathrm{H}$ NMR spectrum recorded on the crude sample obtained from the EDC coupling revealed the presence of the two starting materials, hexacosanoic acid $(\sim 28 \%)$ and phytosphingosine $(\sim 4 \%)$ in addition to the desired product. Although proton integration was unreliable for quantifying the hexacosanoylceramide, the reaction product was easily identified. The amide proton is visible as a doublet at $6.93 \mathrm{ppm}$. There are two-bond HMBC correlations from the amide proton (6.93 ppm) and the methylene resonance (2.12 ppm) to the carbonyl carbon at $173.3 \mathrm{ppm}$, confirming the amide linkage. Three hydroxyl resonances are observed at $\sim 4.20, \sim 4.11$ and $\sim 3.76 \mathrm{ppm}$. Specific assignments for each hydroxyl resonance were not possible due to the broad line widths resulting from chemical exchange broadening. Mass spectral data did not show the presence of starting material seen in Figure 4. Both sheath flow and monospray positive ion electrospray ionization of the hexacosanoic acid starting material yielded the expected $[\mathrm{M}-\mathrm{H}+2 \mathrm{Na}]^{+}$. In the presence of phytosphingosine or hexacosanoylceramide, only the molecular ions of these two compounds were observed, demonstrating preferential positive ionization over hexacosanoic acid. Negative ion sheath flow electrospray ionization yielded signals for both hexacosanoic acid and hexacosanoylceramide along with the cluster species (Figure 5). Molecular ionization efficiencies aside, data yields $\sim 35 \%$ of residual hexacosanoic acid starting material, which is in close agreement with NMR results of the crude sample. Subsequently, the sample was recrystallized in THF (95\% pure). The resolved proton chemical shifts were assigned from the results of COSY, HMQC and HMBC experiments (Scheme 2 and Table 1). Integration of the proton spectrum is consistent with the desired hexacosanoylceramide product $\left(\mathrm{C}_{44} \mathrm{H}_{89} \mathrm{NO}_{4}\right)$. Mass spectral data of the purified sample was also in agreement. 


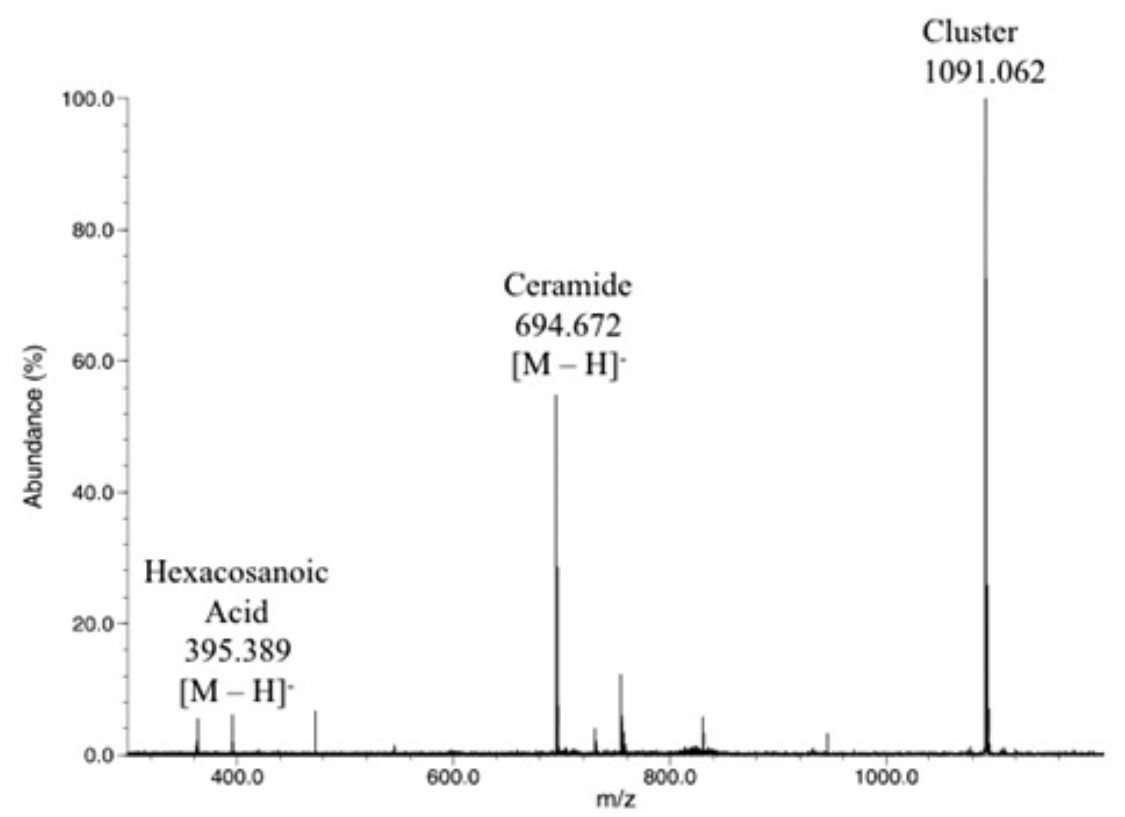

Figure 5. Negative ion sheath flow ESI mass spectrum of reaction A mixture. $[\mathrm{M}-\mathrm{H}]^{-}$is observed for residual hexacosanoic acid, hexacosanoylceramide product, and the cluster species [hexacosanoic acid + hexacosanoylceramide $-\mathrm{H}]^{-}$.

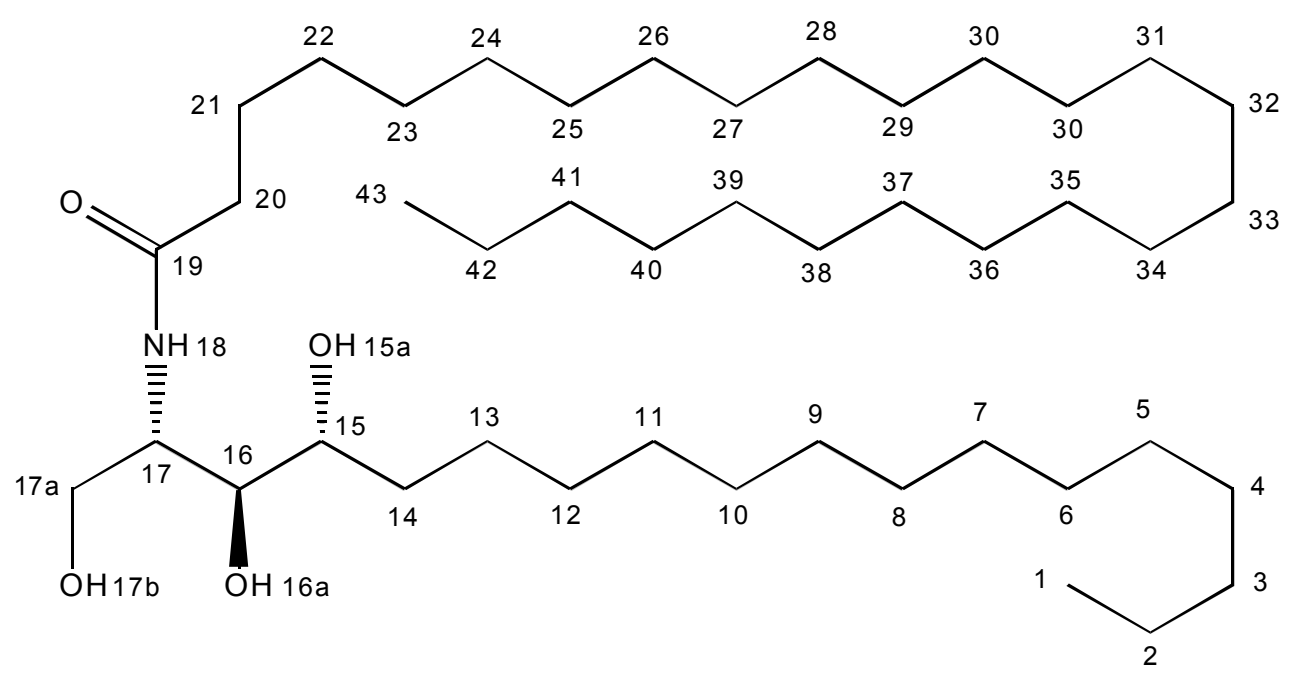

Scheme 2. NMR hexacosanoylceramide carbon atom numbering scheme.

Table 1. Carbon and proton chemical shifts for hexacosanoylceramide in THF- $d_{8}{ }^{1}$.

\begin{tabular}{ccc}
\hline Position & ${ }^{\mathbf{1 3}} \mathbf{C}(\mathbf{p p m})$ & ${ }^{\mathbf{1}} \mathbf{H}(\mathbf{p p m})$ \\
\hline 1 & 14.5 & 0.89 \\
2 & 23.7 & 1.32 \\
3 & 32.9 & 1.3 \\
$4-12$ & $\sim 30.7$ & 1.31 \\
13 & 26.7 & $1.32,1.53$ \\
14 & 34.3 & $1.33,1.71$ \\
15 & 73.2 & 3.44 \\
$15 \mathrm{a}$ & & 3.77 \\
16 & 77.2 & 3.41 \\
\hline
\end{tabular}


Table 1. Cont.

\begin{tabular}{ccc}
\hline Position & ${ }^{\mathbf{1 3}} \mathbf{C}(\mathbf{p p m})$ & ${ }^{\mathbf{1}} \mathbf{H}(\mathbf{p p m})$ \\
\hline $16 \mathrm{a}$ & & 4.21 \\
17 & 53.9 & 4.01 \\
$17 \mathrm{a}$ & 62.5 & $3.61,3.71$ \\
$17 \mathrm{~b}$ & & 4.12 \\
18 & & 6.93 \\
19 & 173.3 & \\
20 & 36.7 & 2.12 \\
21 & 26.6 & 1.59 \\
$22-40$ & $\sim 30.3$ & $\sim 1.31$ \\
41 & 32.9 & 1.3 \\
42 & 23.7 & 1.32 \\
43 & 14.5 & 0.89 \\
\hline
\end{tabular}

${ }^{1}$ Carbons $1-3$ and 40-43 were assigned by comparison of the HMBC spectra of the two starting materials, phytosphingosine and hexacosanoic acid, and the final product hexacosanoylceramide.

\section{Materials and Methods}

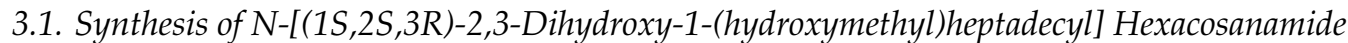

\subsubsection{Samples via EDC/HOBT Coupling}

The reaction is summarized in Scheme 3.

Starting Materials and Products

Phytosphingosine $\left(\mathrm{C}_{18} \mathrm{H}_{39} \mathrm{NO}_{3}, 317.293 \mathrm{Da}\right)$

Hexacosanoic acid $\left(\mathrm{C}_{26} \mathrm{H}_{52} \mathrm{O}_{2}, 396.396 \mathrm{Da}\right)$

Hexacosanoylceramide $\left(\mathrm{C}_{44} \mathrm{H}_{89} \mathrm{NO}_{4}, 695.679 \mathrm{Da}\right)$
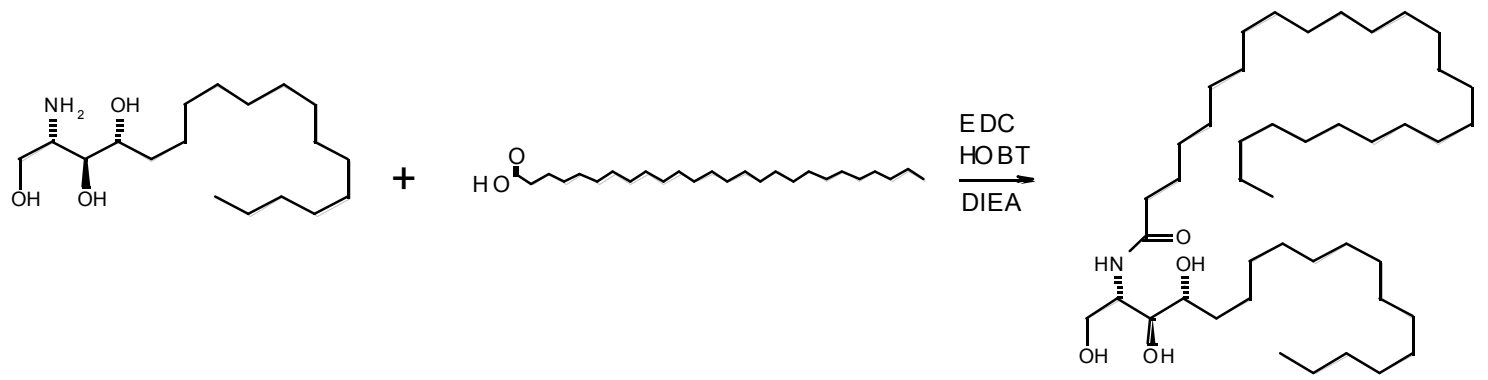

Scheme 3. EDC/HOBT coupling reaction

Hexacosanoic acid $(0.125 \mathrm{~g}, 0.32 \mathrm{mmol}),(2 S, 3 S, 4 R)$-2-aminooctadecane-1,3,4-triol (0.1 g, $0.32 \mathrm{mmol}), \mathrm{N}$-[3-(dimethylamino)propyl]- $\mathrm{N}^{\prime}$-ethylcarbodiimide hydrochloride (EDC, $0.06 \mathrm{~g}$, $0.32 \mathrm{mmol}), 1 \mathrm{H}-1,2,3$-benzotriazol-1-ol hydrate (HOBT, $0.048 \mathrm{~g}, 0.32 \mathrm{mmol}$ ), diisopropylethylamine (DIEA, $0.055 \mathrm{~mL}, 0.32 \mathrm{mmol}$ ) and $20 \mathrm{~mL}$ 1:1 DMF/THF were combined in a $50 \mathrm{~mL}$ round bottom flask fitted with a magnetic stirring bar and a nitrogen inlet. This mixture was stirred for 3 days, subsequently poured into $50 \mathrm{~mL}$ water and filtered. The resulting white solid was dried in vacuo to yield $N$-[(1S,2S,3R)-2,3-dihydroxy-1-(hydroxymethyl)heptadecyl]hexacosanamide (0.2 g, $0.29 \mathrm{mmol}, 91 \%)$.

\subsubsection{Via the Acid Chloride}

The reactions are summarized in Scheme 4 . Hexacosanoic acid $(0.125 \mathrm{~g}, 0.32 \mathrm{mmol})$ and $20 \mathrm{~mL}$ toluene were placed into a $50 \mathrm{~mL}$ round bottom flask fitted with a magnetic stirring bar and a nitrogen 
inlet. Thionyl chloride $(0.046 \mathrm{~mL}, 0.63 \mathrm{mmol})$ was then added dropwise and the reaction heated to reflux for 3 days, cooled and the solvent removed in vacuo. The resulting crude reaction mixture was used in the next step without further purification.
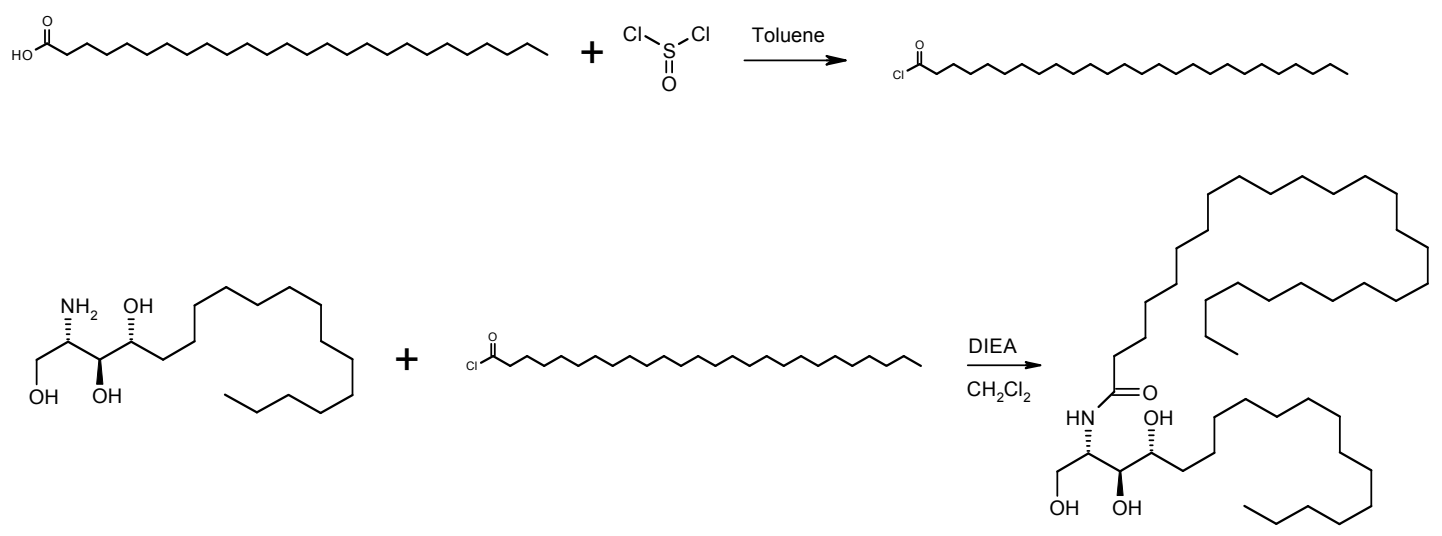

Scheme 4. Hexacosanoylceramide synthesis via the acid chloride.

$(2 S, 3 S, 4 R)$-2-aminooctadecane-1,3,4-triol $(0.1 \mathrm{~g}, 0.32 \mathrm{mmol})$, diisopropylethylamine (DIEA, $0.066 \mathrm{~mL}, 0.38 \mathrm{mmol}$ ) and $20 \mathrm{~mL}$ methylene chloride were placed in a $50 \mathrm{~mL}$ round bottom flask fitted with a nitrogen adapter and a magnetic stirring bar. The crude hexacosanoyl chloride was dissolved in $5 \mathrm{~mL}$ methylene chloride, added dropwise and the reaction stirred for $18 \mathrm{~h}$. The mixture was poured into $50 \mathrm{~mL}$ water and the resulting white precipitate washed with water and dried in vacuo to yield $N$-[(1S,2S,3R)-2,3-dihydroxy-1-(hydroxymethyl)heptadecyl]hexacosanamide (0.12 g, $0.17 \mathrm{mmol}, 54.7 \%)$.

\subsection{Instrumentation}

\subsubsection{T Bruker BioApex II ${ }^{\mathrm{TM}}$ FTICR MS}

The 7T Bruker BioApex II ${ }^{\mathrm{TM}}$ FTICR mass spectrometer (Billerica, MA, USA) was equipped with a Bruker Apollo electrospray source. Experimental control and data processing were accomplished using Bruker XMass software (Version 6.10) running on Windows NT data stations.

\subsubsection{Finnigan FTICR MS NewStar}

The 3T Finnigan Newstar FTICR mass spectrometer (ThermoFinnigan, San Jose, CA, USA) with the standard dual-trap configuration was equipped with a Tachisto $\mathrm{CO}_{2}$ (Needham, MA, USA) laser interfaced to the source trap and an Analytica ESI source (Branford, CT, USA) interfaced to the analyzer trap. Experimental control and data processing were accomplished using Odyssey software (Version 5.0) running on Sun Microsystems (Mountain View, CA, USA) computer stations.

\subsubsection{Nuclear Magnetic Resonance (NMR)}

${ }^{1} \mathrm{H}-\mathrm{NMR}$ spectra were acquired on a Varian Unity Inova $600 \mathrm{MHz}$ spectrometer (Varian Instruments, Palo Alto, CA, USA) equipped with a $5 \mathrm{~mm}$ triple resonance Z-axis pulsed field gradient probe. Proton-decoupled ${ }^{13} \mathrm{C}$ spectra were acquired on a Varian Unity Inova $500 \mathrm{MHz}$ spectrometer equipped with a Nalorac $5 \mathrm{~mm}$ triple nucleus ${ }^{13} \mathrm{C}\left[{ }^{1} \mathrm{H} /{ }^{19} \mathrm{~F}\right]$ probe (Nalorac Cryogens Corp., Martinez, CA, USA). All spectra were recorded at $25^{\circ} \mathrm{C}$. 


\subsection{MS Ionization Methods}

\subsubsection{Standard Monospray Electrospray Ionization}

Samples were dissolved in acetonitrile:water:glacial acetic acid (50:50:0.1\% $v / v)$ to provide $~ 50 \mu \mathrm{M}$ concentrations. The Bruker Apollo ESI source operating conditions in the atmospheric pressure region of the source were: nitrogen concurrent gas $160^{\circ} \mathrm{C}, 10 \mathrm{PSI}$, nitrogen countercurrent gas $160^{\circ} \mathrm{C}, 30$ flow rate (arbitrary units). Samples were delivered at $2-3 \mu \mathrm{L} / \mathrm{min}$ by use of a Cole Parmer 74,900 Series syringe pump to the single sheath needle assembly positioned $45^{\circ}$ off-axis from the entrance capillary. The ESI needle was held at ground, while the endcap and capillary voltages were set at $-3500 \mathrm{~V}$ and $-4000 \mathrm{~V}$, respectively. Nozzle or skimmer voltages in the $10^{-6}$ torr region of the source were held at $110 \mathrm{~V}$, and $15.2 \mathrm{~V}$, respectively. Ions were collected in the accumulation hexapole for approximately $0.5 \mathrm{~s}$. The ion population was transferred to the Bruker ICR Infinity ${ }^{\mathrm{TM}}$ cell for analysis. In addition, $512 \mathrm{~K}$ data points were broadband detected at a Nyquist Frequency of $625 \mathrm{MHz}(\sim m / z$ 200) yielding $0.42 \mathrm{~s}$ of acquisition time. Sixteen transients were co-added followed by Gaussian apodization and one zero fill prior to Fourier transformation. Accurate mass measurements were obtained by external calibration with polypropylene glycol of average mass 425 (Aldrich, Milwaukee, WI, USA).

\subsubsection{Direct Laser Desorption Ionization (DLDI)}

The samples under study were dissolved in THF to yield approximately $10 \% w / v$ concentration. In addition, $100 \mu \mathrm{L}$ of that solution and $100 \mu \mathrm{L}$ of a saturated solution of potassium iodide used as the source of cations dissolved in THF were deposited on a cellulose substrate disk. To remove excess solvent, the sample disk was heated $15 \mathrm{~min}$ at $110^{\circ} \mathrm{C}$. The sample disk was positioned $3 \mathrm{~mm}$ from the source trap plate of the ICR cell via an automatic insertion probe. The Tachisto $\mathrm{CO}_{2}$ laser beam $\left(\lambda=10.6 \mu \mathrm{m}\right.$, power $10^{6}-10^{8}$ watts $/ \mathrm{cm}^{2}$, pulse width $\left.=40-80 \mathrm{~ns}\right)$ was fired at the sample disk producing a spot size of approximately $1 \mathrm{~mm}^{2}$. The potassiated molecular ions were collected and allowed to equilibrate for $2.5 \mathrm{~s}$ in the cell. All ions below $300 \mathrm{~m} / \mathrm{z}$, primarily due to KI, were ejected by a radio-frequency excitation pulse. After a $30 \mathrm{~ms}$ delay to allow ions to equilibrate in the ICR cell, the remaining ions were rf-excited and detected. Thirty-two K data points were acquired at a Nyquist Frequency of $347 \mathrm{kHz}$, and one zero fill was added before Fourier transformation. The transients were not apodized. Only mono-potassiated signals were observed. For a more detailed description of the DLDI-FTICR MS experiments, consult Simonsick and Ross [35] and the $\mathrm{CO}_{2}$ laser references within.

\subsubsection{Sheath Flow Electrospray Ionization}

The samples under investigation were dissolved in THF to a concentration of approximately $50 \mu \mathrm{g} / \mathrm{mL}$. Sodium iodide was added to a methanol solution to yield a concentration of $15 \mu \mathrm{g} / \mathrm{mL}$ $(50 \mu \mathrm{M})$. The ESI needle was held at ground, while the endcap, capillary, and cylinder voltages were set at $-3200,-4000$, and $-2150 \mathrm{~V}$, respectively. Nozzle and skimmer voltages in the $10^{-6}$ torr region of the source were held at $220 \mathrm{~V}$, and $10 \mathrm{~V}$, respectively. The Analytica ESI source was fitted with a triple sheath needle assembly and interfaced to the Finnigan FTMS Newstar system. The samples were sprayed through the inner needle at $15 \mu \mathrm{L} / \mathrm{min}$, the sodium iodide solution in the middle sheath at $30 \mu \mathrm{L} / \mathrm{min}$, and the nitrogen concurrent/sheath and countercurrent gases were held at 60 PSI. Each acquisition contained $128 \mathrm{~K}$ data points with a lower limit of $m / z 200$. Twenty transients were co-added and one zero fill was performed prior to Fourier transformation. Negative ion sheath flow ESI used pure methanol as the sheath liquid with endcap, capillary and cylinder, nozzle/skimmer voltages of $+2800,+3900,+2050,-220$, and $-10 \mathrm{~V}$, respectively.

\subsection{NMR Analysis}

Samples for NMR measurements contained approximately $1 \mathrm{mg}$ of phytosphingosine dissolved in DMSO- $d_{6}$ (Isotec 99.96 atom \% D) or $1.5 \mathrm{mg}$ of hexacosanoylceramide dissolved in THF- $d_{8}$ (Isotec 100.0 atom \% D) in a final sample volume of $0.650 \mathrm{~mL} .{ }^{1} \mathrm{H}$ and ${ }^{13} \mathrm{C}$ chemical shifts were referenced to 
tetramethylsilane (TMS) at $0.00 \mathrm{ppm}$. One-dimensional carbon spectra were acquired with $72 \mathrm{~K}$ data points, a sweep width of $28 \mathrm{kHz}$ and 25,000 transients using a combined recycle delay and acquisition time of $2.3 \mathrm{~s}$. Broadband proton decoupling was achieved by the application of a globally optimized alternating phase rectangular composite pulse (GARP) modulation scheme [43] during the acquisition period and recycle delay.

Proton chemical shift assignments were obtained with pulsed-field gradient correlated spectroscopy (PFG-COSY) [44]. PFG-COSY spectra were acquired with $1 \mathrm{~K}$ complex points in $\mathrm{t}_{2}$ and 1024 points in $t_{1}$ consisting of 1-8 transients per increment. The data was multiplied by a sine-bell apodization function in both dimensions and zero-filled to $4 \mathrm{~K}$ by $2 \mathrm{~K}$ points prior to Fourier transformation.

Carbon chemical shift assignments were made with proton-detected ${ }^{1} \mathrm{H}-{ }^{13} \mathrm{C}$ heteronuclear multiple quantum coherence spectroscopy (HMQC) [45] and pulsed field gradient heteronuclear multiple bond correlation spectroscopy (PFG-HMBC) [46]. Broadband carbon decoupling in the HMQC spectra was accomplished with a GARP 1 [43] composite pulse decoupling scheme. HMQC spectra were recorded with $1 \mathrm{~K}$ complex points in $t_{2}$ and 256 increments in $t_{1}$ with 4-8 transients per increment. The fixed delays were optimized for a ${ }^{1} \mathrm{H}-{ }^{13} \mathrm{C} 1$-bond coupling constant of $140.0 \mathrm{~Hz}$. The data were zero-filled to $2 \mathrm{~K}$ complex points in $t_{2}$ and $1 \mathrm{~K}$ complex points in $t_{1}$ and were multiplied by a Gaussian function in both dimensions prior to Fourier transformation. PFG-HMBC spectra were acquired in the absolute value mode with $1 \mathrm{~K}$ complex points in $\mathrm{t}_{2}$ and 1024 increments in $t_{1}$ with 8-48 transients per increment. The heteronuclear multiple bond fixed delay was set to $65.0 \mathrm{~ms}$ to optimize observation of 2- and 3-bond heteronuclear correlations. All two-dimensional experiments were acquired in the absolute value mode with the exception of the HMQC experiment which was acquired in the hypercomplex mode for phase-sensitive presentation.

\section{Conclusions}

The water soluble phytosphingosine starting material ionizes well by use of standard monospray positive ion electrospray conditions. The non-water soluble starting materials hexacosanoic acid and ceramide reaction products were observed by the use of direct laser desorption and sheath flow electrospray ionization. To visualize all the components in one spectrum, negative ion sheath flow ESI provided the best results and could be interfaced to chromatography if deemed necessary. No single ionization method is a panacea for characterizing all samples, particularly compounds with such different physicochemical properties as discussed here. NMR and mass spectral analysis are complementary. The combination of FTICR MS's high mass accuracy and resolving power with direct laser desorption ionization, sheath flow electrospray ionization, and high field NMR studies provide an efficient methodology for structural characterization of these important biological lipids.

Acknowledgments: We thank Joel Huff and Steve Young of the Merck \& Co. Inc. Medicinal Chemistry Department., West Point, Pennsylvania, and Bruce Neff of DuPont Marshall Laboratories, Philadelphia, Pennsylvania, for their support of this collaborative effort.

Author Contributions: James P. Guare and Randall C. Newton designed and conducted the chemical syntheses. Charles W. Ross III, William J. Simonsick Jr., and Recep W. Celikay designed, conducted, and interpreted the mass spectrometry experiments. Michael J. Bogusky designed, conducted, and interpreted the NMR experiments.

Conflicts of Interest: The authors declare no conflict of interest.

Abbreviations

$\begin{array}{ll}\text { DLDI } & \text { Direct laser desorption ionization } \\ \text { ESI } & \text { Electrospray ionization } \\ \text { FTICR MS } & \text { Fourier transform ion cyclotron resonance mass spectrometry } \\ \text { HPLC } & \text { High performance liquid chromatography } \\ \text { TLC } & \text { Thin layer chromatography } \\ \text { NMR } & \text { Nuclear magnetic resonance } \\ \text { EDC } & N-\left[3-\left(\text { dimethylamino)propyl]- } N^{\prime} \text {-ethylcarbodiimide hydrochloride }\right.\right. \\ \text { HOBT } & 1 \mathrm{H}-1,2,3 \text {-benzotriazol-1-ol hydrate }\end{array}$




$\begin{array}{ll}\text { MALDI } & \text { Matrix-assisted laser desorption ionization } \\ \text { PFG-HMBC } & \text { Pulsed field gradient heteronuclear multiple bond correlation spectroscopy } \\ \text { HMQC } & \text { 2D heteronuclear multiple quantum coherence spectroscopy } \\ \text { HMBC } & \text { 2D heteronuclear multiple bond correlation spectroscopy } \\ \text { COSY } & \text { 2D homonuclear correlation spectroscopy } \\ \text { GARP } & \text { Globally optimized alternating phase rectangular pulse }\end{array}$

\section{References}

1. Gamard, C.J.; Dbaibo, G.S.; Liu, B.; Obeid, L.; Hannun, Y. Selective involvement of ceramide in cytokine-induced apoptosis. Ceramide inhibits phorbol ester activation of nuclear factor кB. J. Biol. Chem. 1997, 272, 16474-16481. [CrossRef] [PubMed]

2. Okazaki, T.; Kondo, T.; Kitano, T.; Tashima, M. Diversity and complexity of ceramide signalling in apoptosis. Cell Signal. 1998, 10, 685-692. [CrossRef]

3. Hannun, Y. Functions of ceramide in coordinating cellular responses to stress. Science 1996, 272, $1855-1858$. [CrossRef]

4. Obeid, L.M.; Hannun, Y. Ceramide: A stress signal and mediator of growth suppression and apoptosis. J. Cell. Biochem. 1995, 58, 191-198. [CrossRef] [PubMed]

5. Miller, H.C.; Esselman, W.S. Modulation of the immune response by antigen-reactive lymphocytes after cultivation with gangliosides. J. Immunol. 1975, 115, 839-843. [PubMed]

6. Miller, H.C.; Chaney, W.G.; Klinhan, N.R.; Essalman, W.S. Regulation of B cell tolerance by murine gangliosides. Cell. Immunol. 1982, 67, 390-395. [CrossRef]

7. Constantino, V.; Fattorusso, E.; Mangoni, A. Glycolipids from Sponges. IV. Immunomodulating glycosyl ceramide from the marine sponge. Tetrahedron 1996, 52, 1573-1578. [CrossRef]

8. Motoki, K.; Kobayashi, E.; Uchida, T.; Fukushima, H.; Koezuka, Y. Radioprotective effects of $\alpha$-galactosylceramides. Bioorg. Med. Chem. Lett. 1995, 5, 705-710. [CrossRef]

9. Plettenburg, O.; Bodmer-Narkevitch, V.; Wong, C. Bacterial glycolipids and analogs as antigens for CD1d-restricted NKT cells. J. Org. Chem. 2002, 67, 4559-4564. [CrossRef] [PubMed]

10. Cremesti, A.E.; Fischl, A.S. Current methods for the identification and quantitation of ceramides: An overview. Lipids 2000, 35, 937-945. [CrossRef] [PubMed]

11. Lee, S.H.; Blair, I.A. Analysis of etheno 2 '-deoxyguanosine adducts as dosimeters of AKR mediated-oxidative stress (Chapter 10) in Aldo-keto reductases and toxicant metabolism. ACS Symp. Ser. 2004, 865, 139-152.

12. Castegnaro, M.; Garren, L.; Gaucher, I.; Wild, C.P. Development of a new method for the analysis of sphinganine and sphingosine in urine and tissues. Nat. Toxins 1996, 4, 284-290. [CrossRef]

13. Lagana, A.; Marino, A.; Fago, G.; Miccheli, A. Determination of free sphingosine in biological systems by HPLC. Ann. Chim. 1991, 81, 721-734.

14. Ribar, S.; Mesaric, M.; Bauman, M. High-performance liquid chromatographic determination of sphinganine and sphingosine in serum and urine of subjects from an endemic nephropathy area in Croatia. J. Chromatogr. B Biomed. Sci. Appl. 2001, 754, 511-519. [CrossRef]

15. Shephard, G.S.; van der Westhuizen, L. Liquid chromatographic determination of the sphinganine/sphingosine ratio in serum. J. Chromatogr. B Biomed. Sci. Appl. 1998, 710, 219-222. [CrossRef]

16. Previati, M.; Bertolaso, L.; Tramarin, M.; Bertagnolo, V.; Capitani, S. Low nanogram range quantitation of diglycerides and ceramide by high performance liquid chromatography. Anal. Biochem. 1996, 233, 108-114. [CrossRef] [PubMed]

17. Roy, S.; Gaudin, K.; Germain, D.P.; Baillet, A.; Prognon, P.; Chaminade, P. Optimisation of the separation of four major neutral glycosphingolipids: Application to a rapid and simple detection of urinary globotriaosylceramide in Fabry disease. J. Chromatogr. B Anal. Technol. Biomed. Life Sci. 2004, 805, 331-337. [CrossRef] [PubMed]

18. Markello, T.C.; Guo, J.; Gahl, W.A. High-performance liquid chromatography of lipids for the identification of human metabolic disease. Anal. Biochem. 1991, 198, 368-374. [CrossRef]

19. McNabb, T.J.; Cremesti, A.E.; Brown, P.R.; Fischl, A.S. The separation and direct detection of ceramides and sphingoid bases by normal-phase high-performance liquid chromatography and evaporative light-scattering detection. Anal. Biochem. 1999, 276, 242-250. [CrossRef] [PubMed] 
20. Olsson, N.U.; Harding, A.J.; Harper, C.; Salem, N., Jr. High-performance liquid chromatography method with light-scattering detection for measurements of lipid class composition: Analysis of brains from alcoholics. J. Chromatogr. B Biomed. Appl. 1996, 681, 213-218. [CrossRef]

21. Rubino, F.M.; Zecca, L.; Sonnino, S. Characterization of a complex mixture of ceramides by fast atom bombardment and precursor and fragment analysis tandem mass spectrometry. Biol. Mass Spectrom. 1994, 23, 82-90. [CrossRef]

22. Rubino, F.M.; Sonnino, S. Characterization of ceramide mixtures by fast atom bombardment and tandem mass spectrometry. NATO ASI Ser. C Math. Phys. Sci. 1996, 475, 417-428.

23. Ivanova, P.T.; Cerda, B.A.; Horn, D.M.; Cohen, J.S.; McLafferty, F.W.; Brown, H.A. Electrospray ionization mass spectrometry analysis of changes in phospholipids in RBL-2H3 mastocytoma cells during degranulation. Proc. Natl. Acad. Sci. USA 2001, 98, 7152-7157. [CrossRef] [PubMed]

24. Rodgers, R.P.; Blumer, E.N.; Emmett, M.R.; Marshall, A.G. Complete compositional monitoring of the weathering of transportation fuels based on elemental compositions from Fourier transform ion cyclotron resonance mass spectrometry. Environ. Sci. Technol. 2000, 34, 1671-1678. [CrossRef]

25. Fridriksson, E.K.; Shipkova, P.A.; Sheets, E.D.; Holowka, D.; Baird, B.; McLafferty, F.W. Quantitative analysis of phospholipids in functionally important membrane domains from RBL-2H3 mast cells using tandem high-resolution mass spectrometry. Biochemistry 1999, 38, 8056-8063. [CrossRef] [PubMed]

26. Marshall, A.G.; Rodgers, R.P.; Blumer, E.N.; Emmett, M.R. Efficacy of Bacterial bioremediation: demonstration of complete incorporation of hydrocarbons into membrane phospholipids from rhodococcus hydrocarbon degrading bacteria by electrospray ionization Fourier transform ion cyclotron resonance mass spectrometry. Environ. Sci. Technol. 2000, 34, 535-540.

27. Byrdwell, W.C. Dual parallel mass spectrometers for analysis of sphingolipid, glycerophospholipid and plasmalogen molecular species. Rapid Commun. Mass Spectrom. 1998, 12, 256-272. [CrossRef]

28. Sandhoff, R.; Hepbildikler, S.T.; Jennemann, R.; Geyer, R.; Gieselmann, V.; Proia, R.L.; Wiegandt, H.; Grone, H.-J. Kidney sulfatides in mouse models of inherited glycosphingolipid disorders: Determination by nano-electrospray ionization tandem mass spectrometry. J. Biol. Chem. 2002, 277, 20386-20398. [CrossRef] [PubMed]

29. Levery, S.B.; Toledo, M.S.; Doong, R.L.; Straus, A.H.; Takahashi, H.K. Comparative analysis of ceramide structural modification found in fungal cerebrosides by electrospray tandem mass spectrometry with low energy collision-induced dissociation of $\mathrm{Li}^{+}$adduct ions. Rapid Commun. Mass Spectrom. 2000, 14, 551-563. [CrossRef]

30. Bielawski, J.; Pierce, J.S.; Snider, J.; Rembiesa, B.; Szulc, Z.M.; Bielawski, A. Sphingolipid Analysis by High Performance Liquid Chromatography-Tandem Mass Spectrometry (HPLC-MS/MS). In Sphingolipids as Signaling and Regulatory Molecules; Landes Bioscience and Spring Science: New York, NY, USA, 2010; pp. 46-59.

31. Selvam, R.; Radin, N.S. Quantitation of lipids by charring on thin-layer plates and scintillation quenching: Application to ceramide determination. Anal. Biochem. 1981, 112, 338-345. [CrossRef]

32. Pettus, B.J.; Kroesen, B.-J.; Szulc, Z.M.; Bielawska, A.; Bielawski, J.; Hannun, Y.A.; Busman, M. Quantitative measurement of different ceramide species from crude cellular extracts by normal-phase high-performance liquid chromatography coupled to atmospheric pressure ionization mass spectrometry. Rapid Commun. Mass Spectrom. 2004, 18, 577-583. [CrossRef] [PubMed]

33. Ramjit, H.G.; Newton, R.; Guare, J.P. A novel coaxial electrospray ionization method for characterizing hexacosanoylceramides by Fourier transform ion cyclotron resonance mass spectrometry. Rapid Commun. Mass Spectrom. 2005, 19, 1257-1262. [CrossRef] [PubMed]

34. Aaserud, D.J.; Prokai, L.; Simonsick, W.J., Jr. Gel permeation chromatography coupled to Fourier transform mass spectrometry for polymer characterization. Anal. Chem. 1999, 71, 4793-4799. [CrossRef] [PubMed]

35. Simonsick, W.J.; Ross, C.W., III. The characterization of novel dispersants, fluorinated surfactants, and modified natural oils by laser desorption Fourier transform ion cyclotron resonance mass spectrometry (LD-FTICR-MS). Int. J. Mass Spectrom. Ion Process. 1996, 158, 379-390. [CrossRef]

36. Aaserud, D.J.; Simonsick, W.J. Modern mass spectrometry for coatings. Prog. Org. Coat. 1998, 34, $206-213$. [CrossRef] 
37. Marto, J.A.; White, F.M.; Seldomridge, S.; Marshall, A.G. Structural characterization of phospholipids by matrix-assisted laser desorption/ionization Fourier transform ion cyclotron resonance mass spectrometry. Anal. Chem. 1995, 67, 3979-3984. [CrossRef] [PubMed]

38. Guan, S.; Wahl, M.C.; Wood, T.D.; Marshall, A.G. Enhanced mass resolving power, sensitivity, and selectivity in laser desorption Fourier transform ion cyclotron resonance mass spectrometry by ion axialization and cooling. Anal. Chem. 1993, 65, 1753-1757. [CrossRef] [PubMed]

39. Wood, T.D.; Ross, C.W., III; Marshall, A.G. Selective parent ion axialization for improved efficiency of collision-induced dissociation in laser desorption/ionization Fourier Transform ion cyclotron resonance mass spectrometry/mass spectrometry. J. Am. Soc. Mass Spectrom. 1994, 5, 900-907. [CrossRef]

40. Corless, S.; Tetler, L.W.; Parr, V.; Wood, D. The usefulness of MALDI and electrospray in the characterisation of synthetic polymers. In Proceedings of the 42nd Annual Conference on Mass Spectrometry and Allied Topics, Chicago, IL, USA, 29 May-3 June 1994; American Society for Mass Spectrometry: Santa Fe, NM, USA, 1994; p. 515.

41. Nielen, M.W.F. Characterization of synthetic polymers by size-exclusion chromatography/electrospray ionization mass spectrometry. Rapid Commun. Mass Spectrom. 1996, 10, 1652-1660. [CrossRef]

42. Simonsick, W.J.; Prokai, L. Gel permeation chromatography coupled to mass spectrometry and tandem mass spectrometry for oligomer analysis. Adv. Chem. Ser. 1995, 247, 41-56.

43. Shaka, A.J.; Barker, P.B.; Freeman, R. Computer-optimized decoupling scheme for wideband applications and low-level operation. J. Magn. Reson. 1985, 64, 547-552. [CrossRef]

44. Hurd, R.E. Gradient-enhanced spectroscopy. J. Magn. Reson. 1990, 87, 422-428. [CrossRef]

45. Bax, A.; Subramanian, S. Sensitivity-enhanced two-dimensional heteronuclear shift correlation NMR spectroscopy. J. Magn. Reson. 1986, 67, 565-569. [CrossRef]

46. Bax, A.; Summers, M.F. Proton and carbon-13 assignments from sensitivity-enhanced detection of heteronuclear multiple-bond connectivity by 2D multiple quantum NMR. J. Am. Chem. Soc. 1986, 108, 2093-2094. [CrossRef]

(C) 2016 by the authors; licensee MDPI, Basel, Switzerland. This article is an open access article distributed under the terms and conditions of the Creative Commons Attribution (CC-BY) license (http://creativecommons.org/licenses/by/4.0/). 